will be a different group of gainers and losers from that in any pathway that is overtly nonsustainable. Environmental taxation will not be popular unless the revenue is directed at those who are made worse off as a result, and at ensuring that the cause of the damage is altered by market signals and strategic subsidy. Such measures will not gain legitimacy in the absence of civic science. The transition to sustainability will be a pro-active and participatory experience of honest trial and error. There can be no blueprint nor any predetermined track. Hence the need for both a compass and a gyroscope.

This is a beautifully written book full of thoughtful insights into environmental policy-making by a person who is clearly sensitive to the political pragmatics of resource management and interest-group bargaining. The text is peppered with examples from the Columbia phenomenon - notably the argument over fish hatcheries, fish ladders, habitat protection for vulnerable species, pricing mechanism to alter the use and amount of water pumped into agriculture, industry, leisure and amenity, and the ever pres-

ent problem of changing biases from well-established prejudices concerning water-use rights and wealth-generating expectations.

Lee captures extremely well the subtle but exciting new roles for science and scientists in a post-Rio world. It remains to be seen how far his call for a more civic and interdisciplinary science will be heeded by those who allocate research budgets, fund training programmes and claim expertise and specialized knowledge. There is a real debate going on in all these areas now that contract-led science is becoming more fashionable and basic research is being starved of money. Civic science must not be the end-point of science: but it does offer a genuinely exciting role for a reformulated interpretation of science in an agonized world that is stumbling its way towards environmental survival. This book is for scientists at large, not just resource managers and technical environmentalists.

Timothy O'Riordan is in the School of Environmental Sciences, University of East Anglia, Norwich NR4 7TJ, UK.

\title{
Social life from the bottom up
}

\author{
W. C. McGrew
}

\begin{abstract}
Primate Behaviour: Information, Social Knowledge, and the Evolution of Culture. By Duane Quiatt and Vernon Reynolds. Cambridge University Press: 1993. Pp. 322. $£ 42.50, \$ 74.95$.
\end{abstract}

HERE is at least the fourth book of this title, but its distinguishing features are revealed in the subtitle. Unlike the other three, which were empirically based or topically organized anthologies, this is an ambitious synthesis by two veterans of primatology. Duane Quiatt and Vernon Reynolds, respectively a US and a British biological anthropologist, attempt to weave together all levels of social life of nonhuman primates, and make a critical comparison of their findings with human primates. The theoretical perspective is broad, taking in both evolutionary and sociocultural anthropological perspectives, but artificial intelligence also makes a contribution. It is a 'high risk/high payoff' undertaking, to use the jargon of optimality theory.

Quiatt and Reynolds start with the premise that information transmission between individuals is the key to understanding social relations. Social cognition allows social knowledge, which underpins relationships, which in turn combine to determine social structure. (The authors rely heavily on the hierarchical view of social life espoused by Robert Hinde.) They carefully build a case, starting from individual acts in their context, showing how tactics and strategies result in net benefits at the individual level of natural selection. At the same time, underlying perceptual and cognitive processes are manifest in sociai cognition (or 'mindreading' as it is sometimes called). Intentional communication or miscommunication shapes relationships, as each individual primate competes or cooperates with her or his fellows.

The final third of the book focuses on human primates, taking the analysis to the highest level of social organization: institutions. Here the emphasis changes from continuities across the order Primates to discontinuities that define human uniqueness. Key parts are assigned to language, marriage, lineage, wealth and family. The conventionalizing of these roles allows the evolutionary transformation that culminates in human culture.

The attempt overall is gallant, but problems arise. Despite offering cogent definitions in principle of such phenomena as social knowledge, pedagogy and institution, these are not framed in empirically testable, operational terms. Thus, we are not told, for example, how to distinguish rule-governed from convention-governed behaviour in the real world, although the authors present this as a contrast between nonhuman and human beings. It may be that only humans assume true roles, but working primatologists might argue that this is very much a matter of definition.
This is compounded by the selective focus of attention among primate taxa, which reports findings almost entirely from Old World monkeys and from chimpanzees. Prosimians and New World monkeys are virtually ignored. Although this might have been justified until recently on the grounds of lack of data, that position is now outdated. To argue that fatherhood as a role is somehow essentially human ignores a mass of work from marmosets and tamarins showing sophisticated familial division of labour in childrearing.

The book's arguments are not well served by a somewhat pedantic writing style, too full of fancy words such as "evidencing", "processual", "solidary" and "juridicial". More curious are terms that seem to be idiosyncratic variations on standard ones: "provisionization" (provisioning), "pairedness" (pair-bonding), "degree of relationship" (relatedness), "matrikin" (maternal kin) and so on. This too often combines with obtuseness to produce a demanding test for the reader, as in: "It may help to address such questions if we make a distinction between the domain of social knowledge ... and the social domain(s) of knowledge, or knowledge in the social domain".

The ideas in the book are notable for their skilful interweaving, rather than their novelty, with heavy debts to Nicholas Humphrey, Robert Trivers, Dorothy Cheney and Robert Seyfarth, and Richard Byrne and Andrew Whiten. More disturbing are the absences: Barbara King's work in the same vein is not mentioned, nor are David Premack and Guy Woodruff's trail-blazing studies on 'theory of mind' in chimpanzees.

The overall result is a useful synthesis of the current state of cognitive primatology, as seen through experienced anthropological eyes, that presents a challenge to readers seeking to make sense of this topical area of research.

W. C. McGrew is in the Departments of Sociology and Anthropology, of Psychology and of Zoology, Miami University, Oxford, Ohio 45056, USA.

\section{Biology in paperback}

Foundations of Cognitive Science edited by Michael I. Posner. MIT Press, $\$ 35$, $£ 24.95$. For a review see Nature 351 , 281 (1991)

The Doctrine of DNA : Biology as Ideology by R. C. Lewontin. Penguin, $£ 5.99$. See Nature 363, 27 (1993).

Life History: An Introduction to Taphonomy and Paleoecology by Pat Shipman. Harvard University Press, \$23.95, $£ 15.95$. See Nature 214, 598 (1981).

Random Walks in Biology by Howard Berg. New edition. Princeton University Press, \$12.95, £10.95. See Nature 310, 258 (1984). 